\title{
Application of A Computer Animation Technique to Assist the Teaching of Pre-Handwriting Skills to Children Difficulties/Dyspraxia with Coordination
}

\author{
Muhammad Fakri Othman ${ }^{1,2}$, Wendy Keay Bright ${ }^{2}$, Norhalina Senan ${ }^{1}$, Suriawati Suparjoh ${ }^{1}$ \\ ${ }^{1}$ Department of Multimedia, Faculty of Computer Science and Information Technology, Universiti \\ Tun Hussein Onn Malaysia, Parit Raja, 86400 Batu Pahat, Johor, Malaysia \\ ${ }^{2}$ Department of Creative Communications, Cardiff School of Art and Design, Cardiff Metropolitan \\ University, Cardiff, United Kingdom
}

\begin{abstract}
We have proposed a method to assist children with coordination difficulties or dyspraxia to improve their handwriting skills. We have chosen an animation technique called 'Rotoscopy', a method that normally been used in animation and film production and adapted it to Rotoscopy Prehandwriting Interface (RPI) prototypes using the interactive whiteboard (IWB) as interaction device. The motivation of this research is to discover how efficient if Rotoscopy is used beyond its normal purposes? Does it give benefits in terms of behavioural and motivational aspect rather than commercial and profit point of view? Implementation of RPI prototypes has taken place through series of workshops with a teacher and a group of children with handwriting difficulties at a special education school in Caerphilly, Cardiff, United Kingdom. In the workshops children were given pre-handwriting activities in two different environments. They have been trained to use RPI prototypes and IWB as well as using pen and paper. Their activities and action has been observed and recorded using video camera. Evaluation method is based-on video analysis of children's pre-handwriting result and their reaction and motivation during the workshop. It was learnt that majority of children who used RPI prototypes and IWB have produced better results in terms of accuracy of the drawing as compared to results of pen and paper activities. Furthermore the children are more motivated to use the prototypes and IWB rather than using pen and paper. The study's contribution includes offering a new way to improve children's prehandwriting skills using computer animation technique and touch-based devices.
\end{abstract}

*Corresponding author: fakri@uthm.edu.my, faothman@,cardiffmet.ac.uk 


\section{Introduction}

Rotoscopy is a traditional animation technique that has been comprehensively adopted in computer animation. It captures human movement in such a way that it can be animated in a simplified form to convey naturalistic actions [1][2]. It is also a technique in which animators trace over live-action film movement for use in animated films [3]. The process involves frame-by-frame projection of moving images to allow the animator to copy every single frame to create a natural-looking animation.

A famous film that used rotoscopy is A Scanner Darkly, produced in 2006 by Richard Linklater using a software called Rotoshop. Originally, rotoscopy technique was invented in 1917 by Max Fleisher for his film, Out of the Inkwell. It is named after projection equipment called the Rotoscope; where pre-recorded live-action film images were projected onto a frosted glass panel and re-drawn by an animator. Recently the device has been replaced by computers, and the technique has been referred to as interpolated rotoscopy. In visual effects industry, rotoscopy refers to the technique of manually creating a matte for an element on a live-action plate to be composited over different background [4]. Figure 1 shows examples of rotoscopy whilst a short animation can been produced through the rotoscopy process using a live action video. In this example, graphics images as well as human motion and body shape from a video sequences were traced manually using rotoscopy system to get the image silhouettes, which are then been transformed to 2D graphics and animation. From the output, we can create a new 2D graphics or character that are different from original object but inherits its shapes and motion.

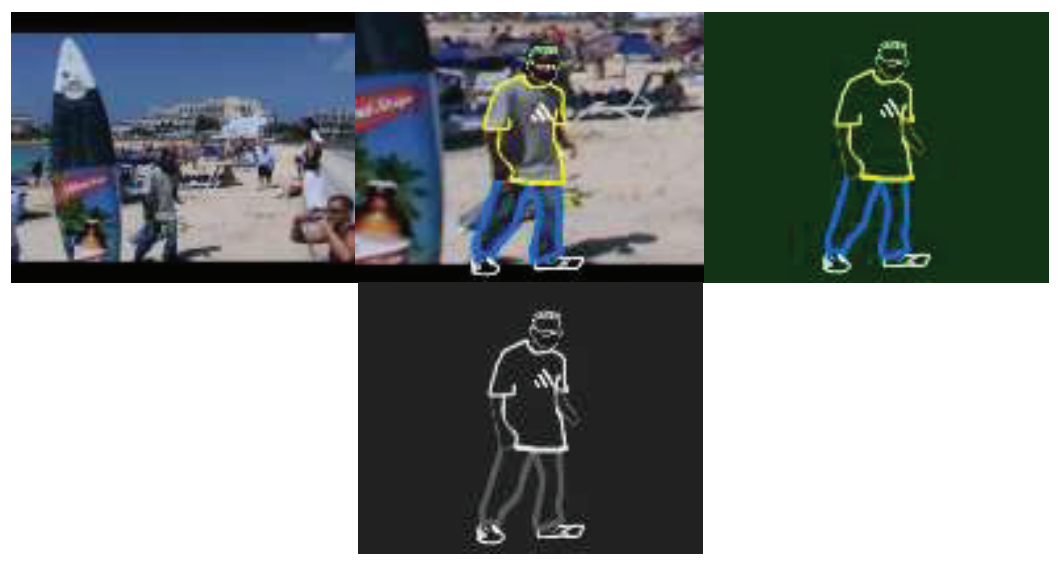

Figure 1. Example of rotoscopy process: from a video to $2 \mathrm{D}$ graphics and animation

\section{Related Works}

\subsection{Rotoscopy and Tracking}

Early studies in Rotoscopy were focused on techniques for 2D graphics and animation, such as Contour Tracking [2] and SnakeToonz [5]. Keyframe-based Tracking [3] was proposed as a technique for rotoscopy and animation, which has been improved by Bi-directional 
Tracking [6]. However, both methods produced 2D results and faced similar difficulties. Rotoscopy typically produces non-photorealistic images and animation as it requires more human effort to trace object contours from captured video sequences, whilst tracking is a process in rotoscopy to capture video to be transformed to 2D or 3D graphics and animation. Though a few tracking algorithms have been introduced, such as Keyframe-based Tracking and Bi-directional Tracking, previous research in rotoscopy and animation focuses more on video and $2 \mathrm{D}$ image rather than producing $3 \mathrm{D}$ output.

\subsection{Rotoscopy, 3D Graphics and Animation}

For 3D graphics and animation, the studies involved production of 3D models from video, as well as to improve the image quality. A real-time 3D model acquisition system [7] was developed to assist user to rotate an object by hand and see a continuously-updated model as the object is scanned. However the system has limited functions and required much human efforts. Another research, 3D objects from photographs and video clip [8] has emerged, but it was only for non-animated 3D images.

More recently, a new method to capture 3D mesh from 2.5D video [9] has been used, but the result has several limitations such as it cannot distinguish between different objects in the scene, the output cannot be viewed from any direction and there is a flickering problem. A 3D sketching system to create 3D models [10] was developed in 2006 but it has problem to generate correct skeleton and accurate sampling of the silhouette. Generally, research of rotoscopy has been established in the area of computer graphics, in particular, tracking, video and animation, though it needs more improvement in terms of quality of output and production time.

\subsection{Rotoscopy and Dyspraxia}

Dyspraxia is a motor learning disability that affects movement and co-ordination due to brain messages not being properly transmitted to the body [11]. A motor learning disability is a condition where people have difficulty planning and organising smooth coordinated movements. It is fairly common in children and adults and is sometimes known as Clumsy Child Syndrome. Other terms, such as developmental co-ordination disorder (DCD), minimal brain dysfunction, and perceptuo-motor dysfunction are also used to describe dyspraxia [12]. According to The World Health Organisation, dyspraxia affects $6 \%$ of all children and the percentage is estimated to increase as high as $10 \%$ [13]. However only a few study related to computer animation technique such as rotoscopy have been undertaken to investigate the potential benefits for people with learning difficulties. This gap provides the main objective and motivation of our research. An application allowing children to be creative and expressive with movement could be beneficial since children with dyspraxia naturally experience movement disorder and may respond well activities that will encourage them to practice their movement and gesture ability. Research on the efficiency of e-learning and multimedia computer technology for children with learning difficulties strongly recommended such approach as it has emerged positive results to the children [14]. 


\subsection{Rotoscopy, Computer System and Handwriting}

Rotoscopy may also appropriate due to the highly visible nature of the graphical output, which is critical for dyspraxic children who have difficulties in hand movement as well as handwriting. A study of sign language co-articulation has been undertaken using the rotoscopy technique [15] as it promotes movement to perform signs using hands. Walden's research [16] found that technical advances of rotoscopy have had aesthetic consequences not just for the quality of image but also to the nature of the actor's performance within animation. In terms of handwriting, Boyle [17] has revealed children with Moderate Learning Difficulties (MLD) like dyspraxia can be helped to improve their handwriting using simple intervention programme like speed of handwriting exercise, with support of other general gross motor coordination test. Meanwhile an investigation by Snape and Nicol [18] using a pen-based computer writing interface, has given positive improvement to children, though it hasn't employed rotoscopy for their system. As shown in Table 1, previous research in rotoscopy has not focused to handwriting, whilst handwriting recognition system hasn't employed rotoscopy as its main solutions nor supporting children with handwriting difficulties. All are different to our approach that applies rotoscopy to assist the teaching of handwriting for children with dyspraxia.

Table 1. Present and proposed rotoscopy systems

\begin{tabular}{|l|l|l|l|l|}
\hline \multirow{2}{*}{ Projects } & \multicolumn{3}{|c|}{ Characteristics } & \multicolumn{1}{|c|}{ Function } \\
\cline { 2 - 5 } & Rotoscopy & $\begin{array}{l}\text { Hand- } \\
\text { writing }\end{array}$ & Dyspraxia \\
\hline $\begin{array}{l}\text { 3D avatars } \\
\text { animation } \\
{[15]}\end{array}$ & $\begin{array}{l}\text { French sign } \\
\text { language } \\
\text { coarticulation }\end{array}$ & YES & NO & NO \\
\hline $\begin{array}{l}\text { Double Take } \\
{[16]}\end{array}$ & $\begin{array}{l}\text { Cinema's actor } \\
\text { and performance } \\
\text { relation }\end{array}$ & YES & NO & NO \\
\hline $\begin{array}{l}\text { Handwriting } \\
\text { recognition } \\
\text { systems [18] }\end{array}$ & $\begin{array}{l}\text { Pen-based } \\
\text { computer writing } \\
\text { interface }\end{array}$ & NO & YES & NO \\
\hline $\begin{array}{l}\text { Speed of } \\
\text { handwriting } \\
\text { exercise [17] }\end{array}$ & $\begin{array}{l}\text { Handwriting using } \\
\text { simple } \\
\text { intervention } \\
\text { programme }\end{array}$ & NO & YES & YES \\
\hline $\begin{array}{l}\text { Proposed } \\
\text { system }\end{array}$ & $\begin{array}{l}\text { Assist } \\
\text { handwriting for } \\
\text { dyspraxic children }\end{array}$ & YES & YES & YES \\
\hline
\end{tabular}

\subsection{Our Research}

Underpinned by theoretic influences on neurological development, animation and movement, and contextualised through a user-centred design approach [19], the research explores the potential of rotoscopy as a motivational tool of learning for children with dyspraxia [20]. A significant aspect of the methodology is to develop a rotoscopy interface using iterative process of continuous prototyping [21]. For the proposed system, the interface is designed to assist dyspraxic children in practising their handwriting skills through movement and performance, rendered visible to them through the projection of actions onto a large surface. We use the combination of $2 \mathrm{D}$ and $3 \mathrm{D}$ animation tools that supports rotoscopy functions such 
as Adobe Flash and Adobe AfterEffects; as well as pen tablet technologies for handwriting tools. Evaluation methods measure the extent to which the animation of movement in a childfriendly graphic form can engage children's motivation [14] and lead to improved handwriting skills [18]. The target group for this study are children at reception class and children with specific learning difficulties, based on the Early Years Foundation System (EYFS) standard [22], as well as their teachers and parents. As a summary, there has been little research investigating the potential of Rotoscopy as a learning tool. However the significance of movement and motor stimulation in child development is well understood. The success of ReacTickles ${ }^{\circledR}[23]$ project as well has given us the idea on interface design for the perceptually mapping of input and output. ReacTickles software was designed as a relaxing and playful experience with technology for children with autism. Figure 2 shows the relation of our research with previous studies in rotoscopy, dyspraxia, and handwriting.

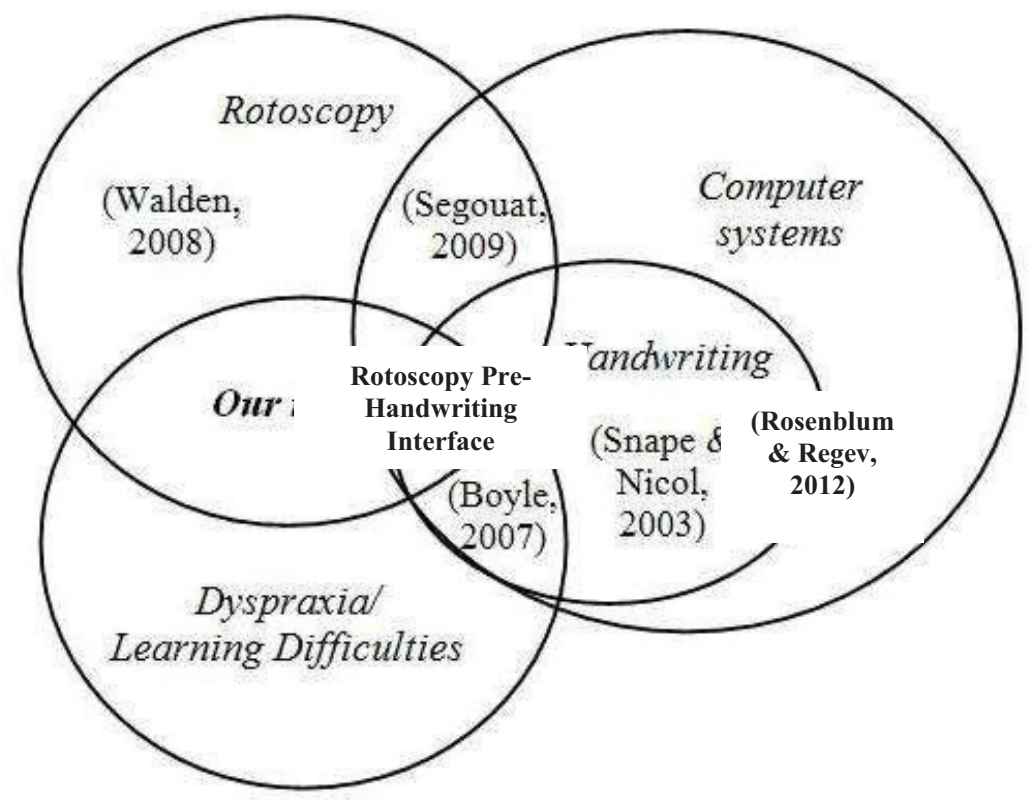

Figure 2. Previous studies in rotoscopy, dyspraxia and handwriting and its relation with our research

\section{User-Centred Design}

Our research has implemented a user centred design approach, which is a combination of ethnography, user observation and informant design [24]. Ethnography and user observation involve user participation in familiar activities in natural settings, which may include exploring prototypes. It can take place at the outset, during, and on completion of a project. Informant design allows children or teachers to be valued as experts or 'native informants', informing designers of key issues that relate to their experience as well as helping to develop early design ideas and testing prototypes in development [25].

The rationale for choosing this method relies on understanding the characteristics of children with learning difficulties, like dyspraxia, who are very subjective in terms of knowledge, skills and cognitive processing; and handwriting is a particular problem that they experienced. User centred design also can reduce the likelihood of system failure as the direct 
relationship between the users and the suppliers means that outcomes are more likely to meet learners' and teachers' real needs [26]. User-centred design approach must be organised to meet with the needs of learners, and with the staff who are likely to include the resulting technology in their pedagogical practices, rather than to meet commercial development requirements [27]. The crucial component for successful practice is ensuring that the adult participants, as well as the children, perceive themselves as learners in the process of designing new technology [28]. By breaking down the distinction between adult 'expert' and child 'user', this method can lead to innovative solutions, and, in the process, engage all parties in the active construction of knowledge. Furthermore, benefits of involving users designing process may include:-

- $\quad$ First-hand experience of end user's needs, interest and requirement.

- Identify design challenges and difficulties at early stage, thus will save time and reduce the cost.

- Achieving educational aims as user's participation gives opportunity to create resources that are embedded in teaching strategies and educational contexts.

\subsection{Contextual Analysis}

We have conducted a contextual analysis by working with experts and offering appropriate activities with prototypes to selected dyspraxia children (end-users). The testing process is fully-guided by suitable experienced professionals and captured on video for further analysis using standardized observation scales. The implementation of prototypes and the training or testing process has taken place at a special education school in Caerphilly, Cardiff, United Kingdom. We have also established a connection with Dyscovery Centre, University of Wales, Newport (http://dyscovery.newport.ac.uk), a special research centre for children with dyspraxia and other learning difficulties. The metrics of testing are video and observation, involving series of different version of prototypes; since all these are techniques applied in ethnography and user observation and informant design approach. We also used Wechsler Intelligence Scales for Children ${ }^{\circledR}$ (WISC) [29] as the evaluation standard. WISC is a special intelligence test designed for children age 6 to 16 to generate their IQ score as well as to diagnose children's learning disability. The results are measured on children's performance, and how the application helps users improve their gross-motor skills, as well as their interest and motivation towards learning.

\subsection{Interactive Whiteboard}

The interactive whiteboard or IWB has been used in classroom to test the prototypes as well pre-handwriting activities. It has been chosen as it is easy to use as it has touch screen mode that allows children to make free hand movements on the screen. The concept is quite similar to pen and graphics tablet but in more spacious movement area. Previous research using penbased computer writing interface [30] has considered it was as efficient as, and produced comparable writing to the pencil and paper. Figure 3 is an example of activities using interactive whiteboard and ReacTickles [31] software for children with autism at the Dyscovery Centre. 


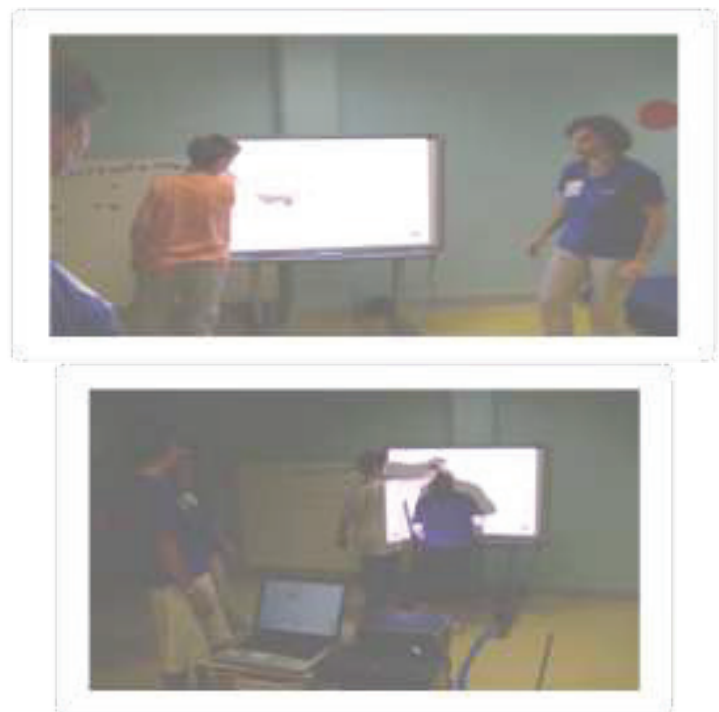

Figure 3. Example of activities using interactive whiteboard

\section{Rotoscopy Pre-Handwriting Interface (RPI) Prototypes}

As our research aims to give children with dyspraxia a playful and physical experience in developing their handwriting skills, we are investigating rotoscopy technique to identify whether motivation and engagement can be increased by using a performance-led embodied approach, which would allow children to practice handwriting using gross motor skills, for example bodily movement and gesture. We also use user-centred design approach to identify the requirements of the system and a context for its application as a learning tool. The development and implementation of the systems are focused on the benefits of using interactive whiteboards [32], as large-scale environments that support gross-motor skills and performance. Rotoscopy technique has been used to trace a projected image on interactive whiteboard screen. The system is developed using 2D and 3D animation software and are utilised been and adapted to respond to user activity in such a way that the mirrored or abstracted image enables the child to visualise the activity and to recognize the projected actions own. This mirroring capacity of the system is vital for the development of social communication and learning [19]. For this reason rotoscopy is chosen to be used as a technique to assist children with dyspraxia, who are known to experience problems with low self-esteem as a result of co-ordination difficulties [33].

The RPI prototypes are designed to assist children with dyspraxia in practising their handwriting skills through movement and performance, rendered visible to them via the projection of actions onto a large surface. Evaluation methods have measured the extent to which the animation of movement in a child-friendly graphic form can engage children's motivation and lead to improved handwriting skills [31]. In particular the RPI prototypes that have been designed and developed are based-on Ripley's Methods for teaching of handwriting to children with dyspraxia [12]. Ripley's method consists of different stages of skills: Prototype 1: Group 1 to Group 4 Symbols, Prototype 2: Numbers, Prototype 3: Circle Letters, Prototype 4: Wiggly Letters and Prototype 5: Child's Name. Meanwhile the RPI activities consist of squiggling, drawing basic shapes, drawing pictures and writing letters 
(Figure 4). These are actions required in children, not only as a pre-handwriting activity before they learn how to write, but to improve their gross-motor skills by using a large screen, such as an interactive whiteboard (IWB), as the interface.

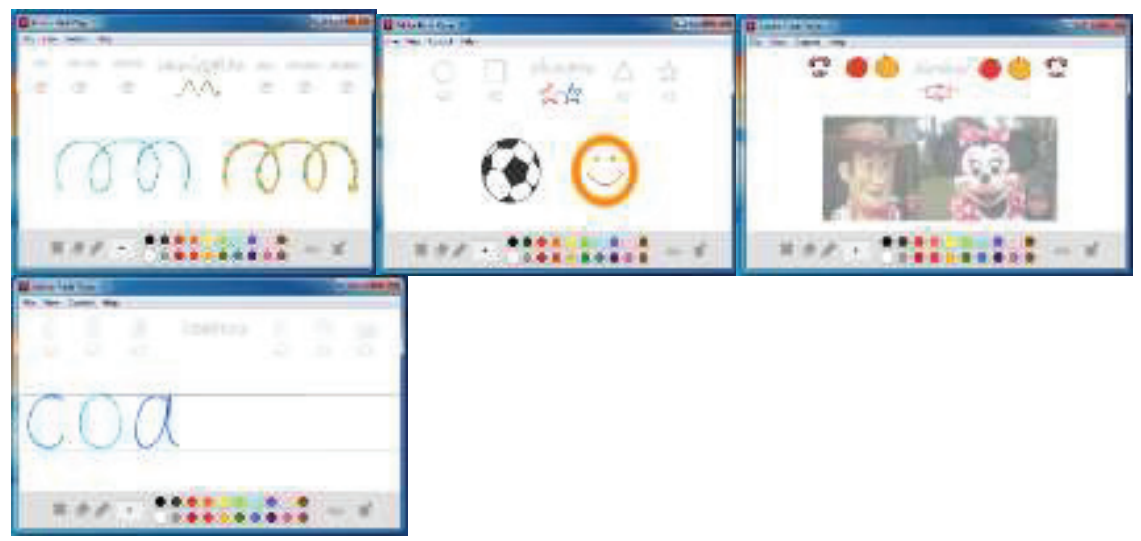

Figure 4. Examples of RPI prototypes: squiggling, shapes, drawing and writing letters

\section{The trial of RPI prototypes}
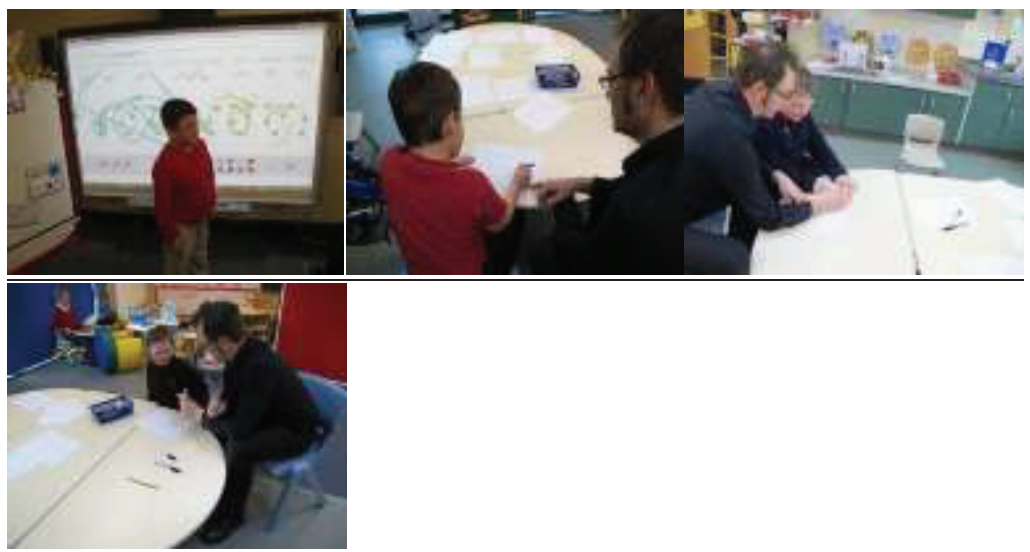

Figure 5. Trial of the first prototype, RPI (Squiggles) and pen and paper (PP) tasks

The trials of the first two of the RPI prototypes, RPI (Squiggles) and RPI (Shapes) has taken place to a group of children with handwriting difficulties at a special school in Caerphilly, Cardiff, United Kingdom. The participants consisted of seven boys and two girls, with writing levels P5 (intermediate) and P6 (advance). The study has obtained an ethical approval from Cardiff Metropolitan University, UK. The participant's consent has also been acquired for research publication. The objectives of the trials are to introduce the system to the target audience, to expose the children to the rotoscopy technique and to adapt it to the system environment as well as to test the functionality of the system prototypes to identify syntax, logical errors and any technical problems. The activities in three trial workshops are introducing the system to the children, trial of the first prototype, RPI (Squiggles) and pen 
and paper (PP) tasks (Figure 5) and the trial of the second prototype, RPI (Shapes) and PP tasks (Figure 6)
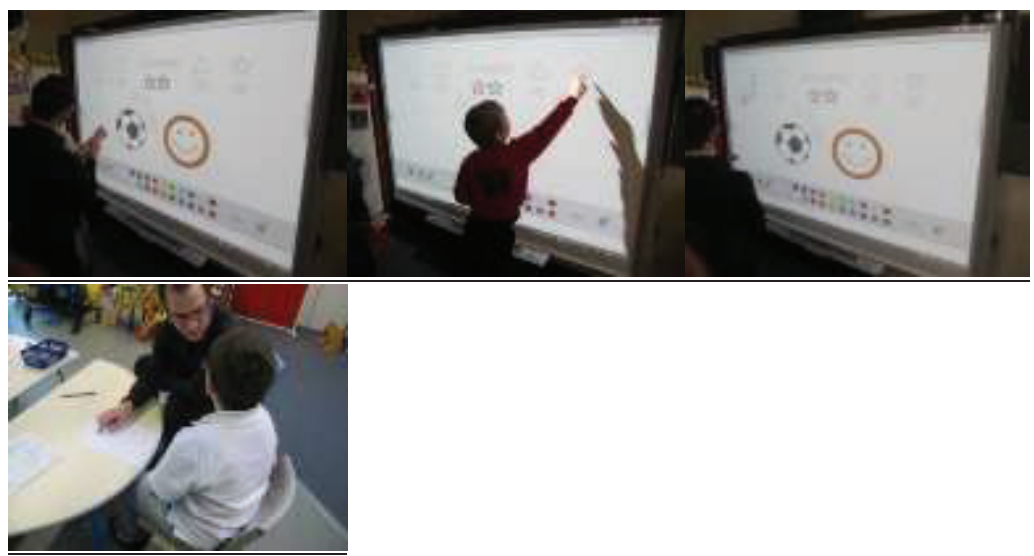

Figure 6. Trial of the second prototype, RPI (Shapes) and pen and paper (PP) tasks

\section{Results and Discussion}

\subsection{Results of squiggling using RPI (Squiggles) for all children}

The first study examined how children squiggle using the first module of RPI prototypes called RPI (Squiggles). There were six activities in this prototype, but only three were tested due to the children's ability, after advice had been taken from the teacher. The first task was Squiggle 1 (Task 1), where the children needed to draw curly lines or squiggles, followed by Squiggle 5 (Task 2), which allowed the children to draw straight lines. Table 2 shows the thumbnail of the results for the squiggling activities (Task 1 and Task 2) drawn by every children using RPI (Squiggles).

Table 2. Results of squiggling using RPI (Squiggles)

\begin{tabular}{|c|c|c|c|}
\hline Task 1: Reference Image & Task 2: Reference Image & Child 5: Task 1 & Child 5: Task 2 \\
\hline Child 1: Task 1 & Child 1: Task 2 & Child 6: Task 1 & Child 6: Task 2 \\
\hline Child 2: Task 1 & Child 2: Task 2 & Child 7: Task 1 & Child 7: Task 2 \\
\hline
\end{tabular}




\begin{tabular}{|l|l|l|l|}
\hline Child 3: Task 1 & Child 3: Task 2 & Child 8: Task 1 \\
\hline Child 4: Task 1 & Child 4: Task 2 & Child 9: Task 1 & Child 9: Task 2 \\
\hline
\end{tabular}

\subsection{Results of squiggling using Pen and Paper (PP) for all children}

The second study was undertaken to assess children's response to squiggles and shapes in a different environment. The study focused on how the children perform basic squiggles using traditional pen and paper (PP) methods with the same squiggle lines they used in the first study, squiggling using RPI (Squiggles). Table 3 shows the thumbnails of the squiggling results for every child involved.

Table 3. Results of squiggling using PP (Children 1 to 9)

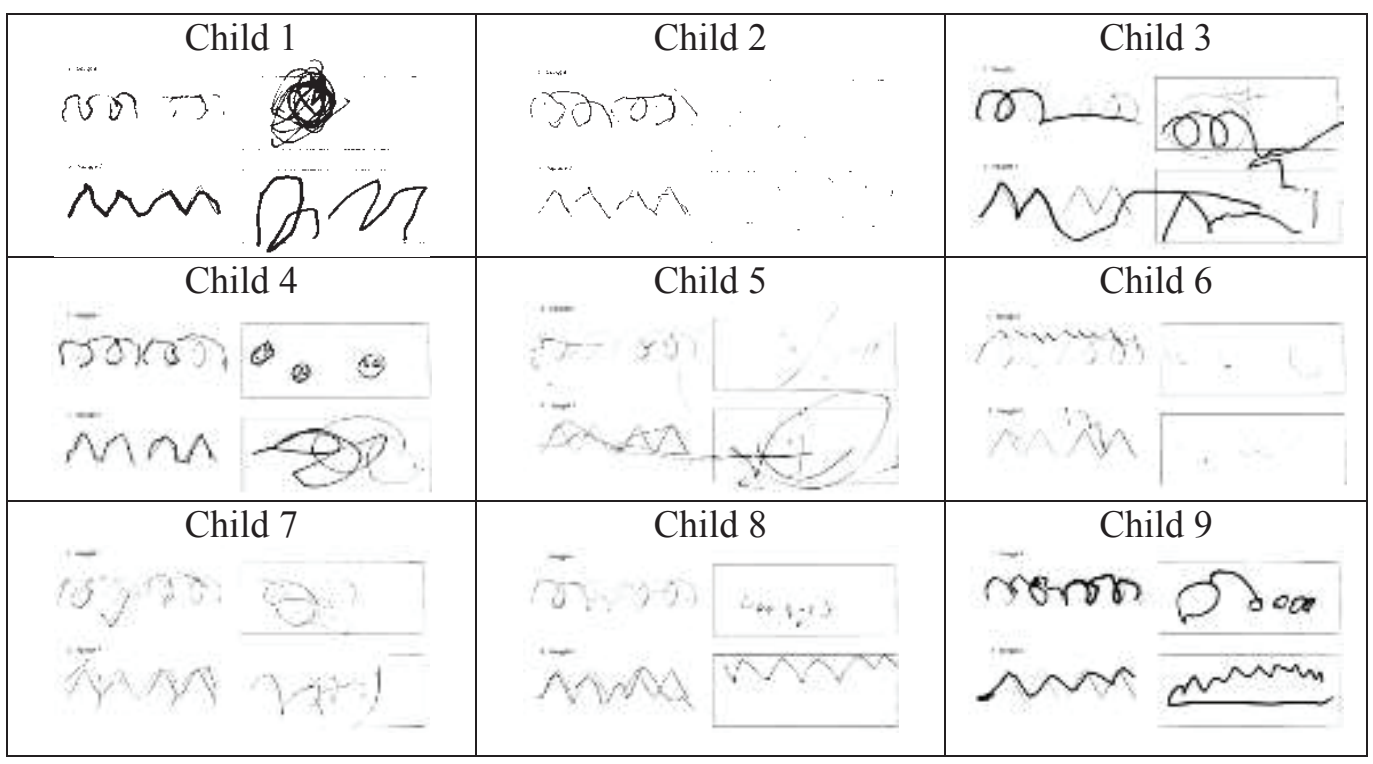

\subsection{Statistical analysis of children's results using RPI (Squiggles) (Task $1 \& 2)$}

The data obtained from children's squiggling using RPI are then analysed using the SPSS package to determine the results' mean score and to compare with the reference images for every task in order to measure the accuracy of children's squiggling or drawings. SPSS is used to identify whether there is a significant difference between the results from children's squiggling compared with the results from the pen and paper (PP) tasks. The spatial 
parameters of the results, which include the width and height of the squiggles and drawings, as well as the number of squiggles or lines for Task 1 and Task 2, are presented in Table 4.

Table 4. Spatial parameters of squiggling results for Task 1 and Task 2

\begin{tabular}{|l|l|l|l|l|l|l|}
\hline Child & $\begin{array}{l}\text { Width } \\
\text { (pixel) }\end{array}$ & $\begin{array}{l}\text { Height } \\
\text { (pixel) }\end{array}$ & $\begin{array}{l}\text { No. of } \\
\text { Squiggles }\end{array}$ & $\begin{array}{l}\text { Width } \\
\text { (pixel) }\end{array}$ & $\begin{array}{l}\text { Height } \\
\text { (pixel) }\end{array}$ & $\begin{array}{l}\text { No. of } \\
\text { Lines }\end{array}$ \\
\hline 1 & 535 & 131 & 4 & 457 & 123 & 4 \\
\hline 2 & 538 & 182 & 4 & 432 & 107 & 3 \\
\hline 3 & 518 & 144 & 1 & 474 & 133 & 1 \\
\hline 4 & 511 & 95 & 4 & 452 & 91 & 4 \\
\hline 5 & 500 & 158 & 2 & 447 & 122 & 2 \\
\hline 6 & 516 & 116 & 1 & 440 & 119 & 2 \\
\hline 7 & 511 & 129 & 4 & 411 & 97 & 4 \\
\hline 8 & 501 & 134 & 3 & 465 & 117 & 3 \\
\hline 9 & 532 & 113 & 3 & 453 & 112 & 3 \\
\hline
\end{tabular}

Table 5. Mean of spatial parameters for Task 1 and Task 2 results

\begin{tabular}{|ll|r|r|r|r|r|r|}
\hline & & \multicolumn{1}{|c|}{ Width1 } & \multicolumn{1}{c|}{ Height1 } & Squiggles & Width2 & Height2 & \multicolumn{1}{c|}{ Lines } \\
\hline $\mathrm{N}$ & Valid & 9 & 9 & 9 & 9 & 9 & 9 \\
& Missing & 0 & 0 & 0 & 0 & 0 & 0 \\
\multirow{2}{*}{ Mean } & & 518.00 & 133.56 & 2.72 & 447.89 & 113.44 & 2.83 \\
\hline
\end{tabular}

The mean for the spatial parameters of both tasks and references are shown in Table 5 above. The comparison of the mean for Task 1 and Task 2 with the mean of the reference images for both tasks (Task 1R and Task 2R) is presented in Table 6 and Table 7 respectively. Both tables show that the mean of children's squiggling parameters for both tasks are close to the parameters of the reference images provided by RPI.

Table 6. Mean of spatial parameters for Task 1 and Task 1R

\begin{tabular}{|c|c|c|c|c|c|c|c|}
\hline & & Width1 & Height1 & Squiggles1 & Width1R & Height1R & Squiggle1R \\
\hline \multirow[t]{2}{*}{$\mathrm{N}$} & Valid & 9 & 9 & 9 & 9 & 9 & 9 \\
\hline & Missing & 0 & 0 & 0 & 0 & 0 & 0 \\
\hline & & 518.00 & 133.56 & 2.72 & 525.00 & 100.00 & 4.00 \\
\hline
\end{tabular}

Table 7. Mean of spatial parameters for Task 2 and Task $2 \mathrm{R}$

\begin{tabular}{|c|c|c|c|c|c|c|c|}
\hline & Width2 & Height2 & Lines2 & Width2R & Height2R & Lines2R \\
\hline $\mathrm{N}$ & Valid & 9 & 9 & 9 & 9 & 9 & 9 \\
\hline & Missing & 0 & 0 & 0 & 0 & 0 & 0 \\
\hline & & 447.89 & 113.44 & 2.83 & 455.00 & 95.00 & 8.00 \\
\hline
\end{tabular}




\subsection{Analysis of Task 1 results}

A Paired Samples Test, or $\boldsymbol{t}$-test, has been implemented to compare the mean of the children's results spatial parameters with the mean of the spatial parameters of the reference images for Task 1 (Task1R), as depicted in Table 8.

Table 8. Paired Samples Test ( $t$-test) for Task 1 and Task 1R

\begin{tabular}{|c|c|c|c|c|c|c|c|c|}
\hline Paired Samples Test & \multicolumn{5}{|c|}{ Paired Differences } & \multirow[t]{3}{*}{$\mathrm{T}$} & \multirow[t]{3}{*}{ Df } & \multirow[t]{3}{*}{$\begin{array}{c}\text { Sig. } \\
(2- \\
\text { tailed) }\end{array}$} \\
\hline & \multirow[t]{2}{*}{ Mean } & \multirow[t]{2}{*}{$\begin{array}{c}\text { Std. } \\
\text { Deviation }\end{array}$} & \multirow[t]{2}{*}{$\begin{array}{l}\text { Std. } \\
\text { Error } \\
\text { Mean }\end{array}$} & \multicolumn{2}{|c|}{$\begin{array}{l}95 \% \text { Confidence } \\
\text { Interval of the } \\
\text { Difference }\end{array}$} & & & \\
\hline & & & & Lower & Upper & & & \\
\hline $\begin{array}{ll}\text { Pair 1 } & \text { Width - } \\
& \text { Width1R }\end{array}$ & -7.000 & 14.142 & 4.714 & -17.871 & 3.871 & -1.485 & 8 & .176 \\
\hline $\begin{array}{ll}\text { Pair } 2 & \text { Height - } \\
& \text { Height1R }\end{array}$ & 33.556 & 25.735 & 8.578 & 13.774 & 53.337 & 3.912 & 8 & .004 \\
\hline $\begin{array}{ll}\text { Pair 3 } & \text { Squiggles - } \\
& \text { Squiggle1R }\end{array}$ & -1.278 & 1.176 & .392 & -2.181 & -.374 & -3.261 & 8 & .012 \\
\hline
\end{tabular}

The $t$-test results in Table 8 show that there was no significant difference for width of Task $1(M=518, S D=14.142)$ and width of Task $1 \mathrm{R}(M=525, S D=0)$ condition $t(8)=1.485, p$ $=0.176$. These results suggest that the width of the children's squiggling results is quite similar to width of the squiggling reference. Specifically, the study results suggest that the accuracy of the children's squiggling is close to the reference image, in terms of the width of the children's squiggling results. However, there was a significant difference in the height of Task $1(M=133.56, S D=25.735)$ and the height of Task $1 \mathrm{R}(M=100, S D=0)$ conditions: $t(8)=3.912, p=0.004$. There was also a significant difference in the number of squiggles $(M=2.72, S D=1.176)$ and the height of the reference $(M=455, S D=0)$ conditions: $t(8)=3.912$, $p=0.012$. Both results suggest that the height of the children's squiggling and the number of squiggles drawn were different when compared with the squiggling reference. These results suggest that the children's squiggling was less accurate in terms of height and number of squiggles. More important the findings show that the efficiency of the Rotoscopy function provided in RPI (Squiggles) has helped children to perform better than in pen and paperbased activity.

\section{Conclusion and Future Works}

Rotoscopy may appropriate for children with dyspraxia as it supports activities that require hand movement. In this case, the input and output device play important role as a medium of communication between children and the methods; as this tangible technologies have a close correspondence in behavioural meaning between input and output. The research provides a contribution to knowledge in terms of offering an interactive tool for developing prehandwriting skills through a bespoke animation technique. For future works, the proposed method may also be easily adapted for teaching handwriting in any languages, for instance 
the Jawi handwriting, as it has the further benefit of being responsive to the widespread availability of touch-based devices, affording direct interaction by tracing lines on background images.

\section{Acknowledgement}

The research publication is seconded by Universiti Tun Hussein Onn Malaysia (UTHM) under Short Term Grant (STG), Vot.U367 and also supported by Gates IT Solution Sdn. Bhd. We would like to thanks Cardiff School of Art and Design, Cardiff Metropolitan University, Cardiff, United Kingdom, Mr Anthony Rhys and pupils of Trinity Fields School and Resource Centre, Caerphilly, Cardiff, UK and the Dyscovery Centre, University of Wales Newport, UK.

\section{References}

[1] M. F. Othman, and W. Keay-Bright, "Using Rotoscopy Technique to Assist the Teaching of Handwriting for Children with Dyspraxia," Proc. The 2010 Third international Conference on Advances in Computer-Human interactions (ACHI 2010). ACHI. IEEE Computer Society, Washington, DC, Feb. 2010, pp. 175-178, doi:http://dx.doi.org/10.1109/ACHI.2010.39

[2] V. Garcia, E., Debreuve, and M. Barlaud, "Contour Tracking Algorithm For Rotoscopy," Proc. ICASSP 2006: IEEE International Conference On Acoustic Speech.

[3] A. Agarwala, A. Hertzmann, D. Salesin, and S. Seitz, “ Keyframe-Based Tracking for Rotoscoping and Animation," Proc. SIGGRAPH, Aug. 2004, pp. 584-591, doi: http://doi.acm.org/10.1145/1186562.1015764.

[4] J. Bouldin, "The Body, Animation and the Real: Race, Reality and the Rotoscope in Betty Boop," Proc. Affective encounters: rethinking embodiment in feminist media studies. Eds. A. Koivunen and S. Paasonen. Turku, FI: Media Studies, 2001, pp. 48-54.

[5] A. Agarwala, "SnakeToonz: a semi-automatic approach to creating cel animation from video," Proc. 2nd ACM International Symposium on Non-photorealistic Animation and Rendering 2001. pp 139-ff.

[6] J. Sun, et al, "Bi-directional tracking using trajectory segment analysis," Proc. SIGGRAPH 2005.

[7] K. Nickel, et al, "3D-tracking of head and hands for pointing gesture recognition in a human-robot interaction scenario,". Proc. Sixth IEEE International Conference on Automatic Face and Gesture Recognition, 2004, pp 565-570.

[8] J Ponce, et al, “3D photography from photographs and video clips," Proc. International Symposium on Core Research, 2003.

[9] N. Snavely, et al, "Stylizing 2.5-D Video,” Proc. NPAR 2006, pp 63-69.

[10] F. Levet, et al, "3D Sketching with Profile Curves," Proc. International Symposium on Smart Graphics, 2006.

[11] M. Boon, Helping Children with Dyspraxia., Jessica Kingsley Publishers, 2001.

[12] K. Ripley, B. Daines, and J. Barrett, Dyspraxia: A Guide for Teachers and Parents., David Fulton Publishers, 1997. 
[13] M.M. Portwood, Understanding developmental dyspraxia: a textbook for students and professionals., David Fulton Publishers, 2000.

[14] A. Savidis, and C. Stephanidis, "Developing inclusive e-learning and eentertainment to effectively accommodate learning difficulties," SIGACCESS Access. Comput. , 83, Sep. 2005, 42-54.

[15] J. Segouat, "A study of sign language coarticulation," SIGACCESS Access. Comput. , 93, Jan. 2009, 31-38, doi:http://doi.acm.org/10.1145/1531930.1531935.

[16] K. L. Walden, "Double Take: Rotoscoping and the processing of performance," Refractory: a journal of entertainment media, Dec. 2008.

[17] C.M. Boyle, "An Analysis Of The Efficacy Of A Motor Skills Training Programme For Young People With Moderate Learning Difficulties," International Journal Of Special Education 2007, Vol 22, No. 1,pp 11-24.

[18] L. Snape, and T. Nicol, T., "Evaluating the effectiveness of a computer based letter formation system for children," Proc. The 2003 Conference on Interaction Design and Children, 2003.

[19] K. Facer, and B. Williamson. "Designing Educational Technologies with Users", Futurelab, 2004 , Available http://www.futurelab.org.uk/resources/documents/handbooks/designing_with_users.pd f

[20] W. Keay-Bright, "Tangible Technologies as Interactive Play Spaces for Children with Learning Difficulties", The International Journal of Technology, Knowledge and Society, 2008, Volume 4, 111-120.

[21] M. Buchenau, and J. F. Suri, "Experience prototyping," Proc. The 3rd Conference on Designing Interactive Systems: Processes, Practices, Methods, and Techniques; August 17 - 19, Aug. 2000, doi: http://doi.acm.org/10.1145/347642.347802.

[22] The Early Year Foundation Stage Standards. Available at: http://www.standards.dfes.gov.uk/eyfs/site/index.htm.

[23] W. Keay-Bright, "Can Computers Create Relaxation? Designing ReacTickles ( Software with Children on the Autistic Spectrum," CoDesign, 3, (2), 2007, pp. 97-110.

[24] J. Gulliksen, B. Goransson, I. Boivie, S. Blomkvist, J. Persson, A. Cajander, "Key principles for user-centred systems design," Behaviour \& Information Technology, Vol. 22, no. 6, Nov.-Dec. 2003, pp. 397-409.

[25] E. Mazzone, J. C. Read, and R. Beale, "Understanding Children's Contributions during Informant Design," The 22nd BCS British-HCI 2008, Liverpool, UK.

[26] A. Druin, "Cooperative Inquiry: Developing New Technologies for Children with Children," Proc. The SIGCHI Conference on Human Factors in Computing Systems: the CHI Is the Limit, ACM, New York, 1999, pp. 592-599, doi:http://doi.acm.org/10.1145/302979.303166.

[27] E. Branton, "Developing a Child-Centred Design Process," Futurelab, 2003, Available at: http://www.futurelab.org.uk/resources/publications reports articles/web articles/Web Article592.

[28] B. Williamson, "The Participation of Children in the Design of New Technology," Futurelab, 2003, Available at: 
http://www.futurelab.org.uk/resources/publications_reports_articles/discussion_papers/ Discussion_Paper396.

[29] E. Kaplan, D. Fein, and J. Kramer, "Wechsler Intelligence Scale for Children ${ }^{\circledR}$ Fourth Edition Integrated," 2004, Available at: http://www.pearsonassessments.com/HAIWEB/Cultures/enus/Productdetail.htm?Pid=015-8982-800

[30] J.C. Read, S. MacFarlane, and M. Horton, "The Usability of Handwriting Recognition for Writing in the Primary Classroom," People and Computer XVIII Design for Life, Springer, London, 2004, doi:10.1007/b138141.

[31] W. Keay-Bright, "Designing Playful Sensory Experiences with Interactive Whiteboard Technology: The Implication for Children on the Autistic Spectrum," EAD $07,2007$.

[32] M. Horton, and J. C. Read, "Interactive Whiteboards in the Living Room? Asking Children about their Technologies," The 22nd BCS British-HCI 2008, Liverpool, UK.

[33] S.E. Henderson, and L. Henderson, "Toward An Understanding of Developmental Coordination Disorder: Terminological and Diagnostic Issues," Neural Plasticity 2003, Vol.10, No. 1-2. 